\title{
Preventive effect of Ibrolipim on suppressing lipid accumulation and increasing lipoprotein lipase in the kidneys of diet-induced diabetic minipigs
}

\author{
Yi Liu ${ }^{1,2 \dagger}$, Zong Bao Wang ${ }^{1 *}$, Wei Dong Yin ${ }^{3}$, Qin Kai Li ${ }^{3}$, Man Bo Cai ${ }^{3}$, Jian Yu' ${ }^{1}$ Hong Guang Li, ${ }^{1,2}$, Chi Zhang ${ }^{3}$ \\ and Xiu Hong $\mathrm{Zu}^{3}$
}

\begin{abstract}
Background: The role of renal lipoprotein lipase (LPL) per se in kidney diseases is still controversial and obscure. The purpose of this study was to observe the preventive effects of Ibrolipim, a LPL activator, on lipid accumulation and LPL expression in the kidneys of minipigs fed a high-sucrose and high-fat diet (HSFD).

Methods: Male Chinese Bama minipigs were fed a control diet or HSFD with or without $0.1 \mathrm{~g} / \mathrm{kg} /$ day Ibrolipim for 5 months. Body weight, plasma glucose, insulin, lipids, LPL activity, and urinary microalbumin were measured. Renal tissue was obtained for detecting LPL activity and contents of triglyceride and cholesterol, observing the renal lipid accumulation by Oil Red O staining, and examining the mRNA and protein expression of LPL by real time PCR, Western Blot and immunohistochemistry.

Results: Feeding HSFD to minipigs caused weight gain, hyperglycemia, hyperinsulinemia, hyperlipidemia and microalbuminuria. HSFD increased plasma LPL activity while it decreased the mRNA and protein expression and activity of LPL in the kidney. The increases in renal triglyceride and cholesterol contents were associated with the decrease in renal LPL activity of HSFD-fed minipigs. In contrast, supplementing Ibrolipim into HSFD lowered body weight, plasma glucose, insulin, triglyceride and urinary albumin concentrations while it increased plasma total cholesterol and HDL-C. Ibrolipim suppressed the renal accumulation of triglyceride and cholesterol, and stimulated the diet-induced down-regulation of LPL expression and activity in the kidney.

Conclusions: Ibrolipim exerts renoprotective and hypolipidemic effects via the increase in renal LPL activity and expression, and thus the increased expression and activity of renal LPL play a vital role in suppressing renal lipid accumulation and ameliorating proteinuria in diet-induced diabetic minipigs.
\end{abstract}

Keywords: Lipoprotein lipase, Lipoprotein lipase activator, Lipid accumulation, Diabetic nephropathy, Swine, Miniature

\section{Introduction}

It is now increasingly accepted that abnormal lipid metabolism and renal accumulation of lipids play an important role in the pathogenesis of diabetic nephropathy (DN) [1-3]. Numerous experimental studies have shown the accumulation of triglyceride and cholesterol in the kidney of animal models fed by a diet rich in

\footnotetext{
* Correspondence: wangzb65@hotmail.com

† Contributed equally

'Department of Laboratory Animal Science, School of Pharmacy and Life Science, University of South China, Hengyang, Hunan 421001, China Full list of author information is available at the end of the article
}

cholesterol and (or) saturated fat and the role of dyslipidemia in promoting kidney damage [4-6]. Our recent works have suggested that feeding high-fat/highsucrose/high-cholesterol diet to minipigs induces insulin resistance $[7,8]$, moderate glomerulosclerosis and earlystage DN [8]. Understanding the mechanisms whereby lipids initiate and augment DN is an important unresolved question.

Lipoprotein lipase (EC 3.1.1.34; LPL) plays a central role in lipid metabolism and transports by catalyzing the hydrolysis of the triglyceride (TG) component of circulating chylomicrons (CM) and very-low-density 
lipoproteins (VLDL) to provide non-esterified fatty acids and 2-monoacylglycerol for tissue utilization [9]. Considering tissue-specific regulation and effects of LPL in lipid metabolism [10], the question arises whether LPL is involved in the mechanism of DN. LPL is expressed in mesangial and/or tubular epithelial cells, and localizes to the endothelial cells as in the blood vessels $[11,12]$. LPL enhances VLDL binding to glomerular mesangial cells and induces proliferation and platelet-derived growth factor (PDGF) expression independent of LPL's familiar role in triglyceride hydrolysis [13]. Contradictorily, Li et al [14] find that VLDL-induced triglyceride accumulation in human mesangial cells is mainly mediated by the enzymolysis action of LPL. On the contrary, there are many reports that LPL expression and activity in the heart, skeletal muscle, and adipose tissues are suppressed in humans and experimental animals with kidney disease [15-18]. In any case, these conflicting results suggest that LPL may be important in mediating the initiation and/or progression of renal disease. In view of the strong connection between LPL and kidney disease, however, it is surprising that there are few direct studies on the role of renal LPL. It is unknown, up to now, whether changing the expression of LPL in kidney per se influences renal lipid metabolism and contributes to the progression of $\mathrm{DN}$ in vivo.

Ibrolipim (NO-1886) is a novel compound that has been reported to increase LPL activity and mass in postheparin plasma and LPL mRNA and activity in adipose tissue, myocardium and skeletal muscle, resulting in a reduction of plasma TG with concomitant elevation of high-density lipoprotein cholesterol (HDL-C) in rats [19-21]. Furthermore, Ibrolipim decreases visceral and subcutaneous fat accumulation and ectopic lipid deposition in the heart, skeletal muscle, liver and pancreas in diet-induced diabetic animal models $[7,22,23]$. In rat model of nephrotic syndrome induced by adriamycin and a high-protein diet, Ibrolipim reduces plasma creatinine $(\mathrm{Cr})$, blood urea nitrogen and proteinuria, and ameliorates tubulointerstitial lesions [24]. However, the mechanisms responsible for the renoprotective effect of Ibrolipim in nephrosis are not fully understood. Moreover, whether Ibrolipim affects the expression of LPL and lipid accumulation in kidney is still unknown.

The purposes of the present study, therefore, are to examine (a) whether there is LPL expression in the kidney of Chinese Bama minipigs, (b) whether the highsucrose and high-fat diet causes renal lipid accumulation and influences renal LPL expression, (c) whether administration of Ibrolipim can suppress diet-induced lipid accumulation and improve renal injury through changing renal LPL expression, and (d) whether LPL plays an important role in the pathogenesis of $\mathrm{DN}$.

\section{Materials and methods Materials}

Ibrolipim (NO-1886), 4-diethoxyphosphorylmethyl- $\mathrm{N}$-(4bromo-2-cyanophenyl) benzamide (CAS 133208-93-2), in powder form was synthesized in the New Drug Research Laboratory of Otsuka Pharmaceutical Factory Inc. (Tokushima, Japan). Antibody against LPL was purchased from Boster Biotech, Inc. (Wuhan, China). Immunohistochemical kits were used from the EliVision $^{\mathrm{TM}}$ plus HRP System (Maixin Biotech Inc., Fuzhou, China). All other chemicals used were high-grade commercially available products.

\section{Animals}

Fifteen male Chinese Bama miniature pigs, 3 to 4 months, were obtained from the Laboratory Animal Center of the Third Military Medical University (Chongqing, China). They were housed in single pens under controlled conditions (temperature of $20 \pm 2^{\circ} \mathrm{C}$ and relative humidity between $30 \%$ to $70 \%$ ) and randomized into three groups with similar body weight: $\mathrm{n}=5$ in the normal control diet (CD) group; $\mathrm{n}=5$ in the high sucrose and fat diet (HSFD) group; $\mathrm{n}=5$ in the HSFD supplemented with $0.1 \mathrm{~g} / \mathrm{kg}$ body weight/day Ibrolipim (HSFD +Ibrolipim) group. The HSFD used in this study was 51\% normal swine diet supplemented with $37 \%$ sucrose, $10 \%$ lard, and 2\% cholesterol [8]. The amount of daily fodder was $4 \%$ weight of minipigs which were fed three times a day. Water was available ad libitum. Body weights were recorded every month, and the study period was 5 months. All experiments were performed according to the guidelines of the Animal Ethics Committee of the University of South China (No. 2005-016).

\section{Biochemical analysis of plasma and urine}

Fasting blood samples were collected from the orbital sinus for plasma parameters at the end of each month. Glucose, TG, total cholesterol (TC) and HDL-C were measured by commercial enzymatic method kits (Rongsheng Biotech Inc., Shanghai, China). Insulin was assayed by a radioimmunoassay kit (China Institute of Atomic Research, Beijing, China). Homeostatic model assessment (HOMA) as the estimate of insulin resistance was calculated by the formula: insulin $\times$ glucose/ $22.5[25]$.

An hour after food consumption at the end of $5^{\text {th }}$ month, heparin $(150 \mathrm{U} / \mathrm{kg})$ was injected into a vein in one ear, and 10 min later blood was collected from a vein in the other ear. The plasma was measured for LPL activity by an immunochemical method described previously [26] using glycerol tri[1- $\left.{ }^{14} \mathrm{C}\right]$ oleate as substrate and selective blocking of hepatic lipase activity with antiserum to hepatic lipase. 
Randomly obtained urine samples in the morning were used for determination of microalbumin (mALB) and $\mathrm{Cr}$ at $0,2,4$ and 5 months. Urinary mALB was measured by immunoturbidimetry (Mingdian Biotech Inc., Shanghai, China). Plasma and urinary $\mathrm{Cr}$ were measured by using the Jaffe method (Jianchen Biotech Inc., Nanjing, China). The urinary mALB to $\mathrm{Cr}$ ratio was calculated [27].

\section{Biochemical analysis in renal tissue}

At the end of the experimental period, the animals were killed by exsanguination under sodium pentobarbital anaesthesia. Left kidneys were removed and weighed, and calculated the kidney weight index (left kidney weight/body weight ratio, $\mathrm{g} / \mathrm{kg}$ ).

Total lipids were extracted from $1 \mathrm{~g}$ of right kidneys by the method of Bligh and Dyer [28]. Tissue TC and TG were analyzed by using the enzymatic method with commercial kits (Rongsheng), and the protein concentration was measured by the BCA Assay Kit (Pierce, Rockford, IL, USA).

Renal heparin-triggered LPL activity was measured as reported previously $[19,26]$. A specimen of kidney was homogenised in $50 \mathrm{mmol} / \mathrm{l} \mathrm{NH}_{4} \mathrm{Cl}$ buffer $(\mathrm{pH} \mathrm{8.5)}$ and incubated with buffer containing heparin for $60 \mathrm{~min}$ at $0^{\circ} \mathrm{C}$. The suspension was then centrifuged, and the supernatant was used to measure LPL activity as described above.

\section{Quantitative real-time PCR}

Total RNA was isolated from right kidneys by TriZol (Invitrogen, Carlsbad, CA, USA) method. Then, cDNA was synthesized with Invitrogen SuperScrip preamplification system. To investigate the expression of LPL mRNA, real-time PCR (Rotor-Gene 3000 real-time analyzer, Corbett Research, Mortlake, Australia) was performed with SYBR Green JumpStart Taq ReadyMix kit (Sigma-Aldrich, St. Louis, MO, USA). The porcine gene specific sequence of LPL primer was forward 5'-CGA AGT ATT GGC ATC CAG AAA C-3' and reverse 5'TTG ATC TCA TAG CCC AAG TTG TT-3'. The relative amount of LPL mRNA was normalized to the expression of internal control $\beta$-actin in each sample. The sequence of $\beta$-actin primer was forward 5'-CCT GTA CGC CAA CAC AGT GC-3' and reverse 5'-ATA CTC CTG CTT GCT GAT CC-3'. All the data were calculated from triplicate reactions.

\section{Western blotting}

Proteins were extracted from left kidneys by using Protein Extraction Kit (G-Biosciences, St Louis, MO, USA). After centrifugation, supernatant was obtained to determine the protein concentration by $\mathrm{BCA}$ method (Pierce). Protein samples $(10 \mu \mathrm{g})$ were subjected to SDS-PAGE $(10 \% \mathrm{w} / \mathrm{v})$ and then transferred to nitrocellulose membranes. Membranes were blocked in $5 \%$ dried milk in Tris-buffered saline with Tween, incubated with anti-LPL (1:400 dilution), followed by horseradish peroxidase-labeled anti-rabbit IgG (1:1000 dilution), and then developed by using the enhanced chemiluminescence detection kit (Amersham Biosciences, Piscataway, NJ, USA) and XAR sensitive film (Kodak, Rochester, NY, USA). The signals were quantified by using the Fluor-S MultiImager system (Bio-Rad Laboratories, Hercules, CA, USA). The LPL protein level was assessed by densitometry with $\beta$-actin (Sigma-Aldrich) as a control.

\section{HE staining and Oil Red $O$ staining}

Paraffin sections were stained for hematoxylin and eosin (HE). Frozen sections were used for Oil Red O staining to determine the renal accumulation of neutral lipid. The area of lipid droplets, appeared as red spots, was captured in more than 5 randomly chosen digital photographs $(\times 200)$ made with the Olympus microscope system (Tokyo, Japan), and quantitatively measured using Image-Pro Plus 6.0 software (Media Cybernetics, Bethesda, MD, USA), and then calculated as a percentage of the field area in each section. The mean area for each minipig in each group was calculated and compared in a blinded manner by the renal pathologists.

\section{Immunohistochemistry}

Kidney sections were deparaffinized, hydrated and then preincubated with $0.1 \%$ trypsin for $30 \mathrm{~min}$ at room temperature. After quenching the endogenous peroxidase by immersion in 3\% hydrogen peroxide for $10 \mathrm{~min}$, sections were incubated at $4^{\circ} \mathrm{C}$ overnight with polyclonal antibodies against LPL diluted to 1:100, then subsequently incubated with polymerized HRP-labeled goat anti-rabbit IgG for $1 \mathrm{~h}$ at $4^{\circ} \mathrm{C}$. The antigen was visualized with diaminobenzidine and counterstained with hematoxylin. Negative controls were included with substitution of the primary antibodies with $10 \%$ non-immune goat serum.

\section{Statistical analysis}

Results are expressed as mean \pm SD by using the SPSS version 17 software. The $\mathrm{mALB} / \mathrm{Cr}$ ratio was log-transformed to approximate a normal distribution. Comparisons among the three groups were analyzed for statistical significance by using one-way analysis of variance, followed by LSD- $t$ test for multiple comparisons. Statistical analysis for histological study was performed by using a nonparametric Mann-Whitney test. Correlation analysis was performed using Pearson's test. $P$ values less than 0.05 were considered significant. 


\section{Results}

Effects of Ibrolipim on body and kidney weights in minipigs

The body weights of three groups were linearly elevated with feeding duration. Body weight gain was significantly higher in the HSFD group than in the CD group, whereas it was suppressed in the HSFD+Ibrolipim group compared with the HSFD group in the 4th and 5 th months (Table 1 ). There was no significant difference in the left kidney weight index among the three groups $(C D, 3.42 \pm 0.51 \mathrm{~g} / \mathrm{kg}$; HSFD, $2.89 \pm 0.71$ $\mathrm{g} / \mathrm{kg}$ and HSFD+Ibrolipim, $3.58 \pm 0.47 \mathrm{~g} / \mathrm{kg}, P=$ 0.199).

Effects of Ibrolipim on plasma parameters in minipigs As shown in Table 1, plasma glucose, insulin, TG, TC and HDL-C concentrations were significantly increased in the HSFD group over the control group with feeding program. Treatment with Ibrolipim lowered plasma glucose, insulin and TG concentrations to be below those in the HSFD group. However, administration of
Ibrolipim in the HSFD caused an increase of plasma TC and HDL-C, even higher than in the HSFD group. The degree of insulin resistance calculated by HOMA was high in HSFD-fed minipigs after 2 months, and suppressed in the HSFD+Ibrolipim group compared with the HSFD group.

\section{Effects of Ibrolipim on renal function in minipigs}

As shown in Table 2, the urinary $\mathrm{mALB} / \mathrm{Cr}$ ratio was significantly increased from the 4th month of HSFDfeeding compared with that of CD-feeding. Ibrolipim supplementation to HSFD markedly decreased the ratio compared with HSFD-feeding. No significant changes were observed in Cr levels of plasma and urine among three groups.

\section{Effects of Ibrolipim on renal lipid accumulation in minipigs}

The feeding of HSFD increased the contents of TC and TG in the renal tissues, and these increases were suppressed by the treatment with Ibrolipim (Table 3 ).

Table 1 Body weight, fasting plasma glucose and lipid metabolites in Chinese Bama minipigs

\begin{tabular}{|c|c|c|c|c|c|c|}
\hline Parameters & Baseline & 1 month & 2 months & 3 months & 4 months & 5 months \\
\hline \multicolumn{7}{|l|}{ Body weight (kg) } \\
\hline CD & $6.04 \pm 1.24$ & $9.22 \pm 1.29$ & $10.28 \pm 1.51$ & $12.34 \pm 1.73$ & $14.35 \pm 2.14$ & $16.85 \pm 3.74$ \\
\hline HSFD & $6.04 \pm 2.12$ & $8.90 \pm 2.68$ & $10.76 \pm 2.61$ & $14.18 \pm 4.25$ & $18.50 \pm 5.31 *$ & $23.55 \pm 7.46^{* *}$ \\
\hline HSFD+lbrolipim & $6.02 \pm 1.10$ & $8.48 \pm 1.65$ & $10.08 \pm 1.84$ & $13.02 \pm 2.50$ & $14.40 \pm 2.51 \#$ & $16.56 \pm 3.83$ \#\# \\
\hline \multicolumn{7}{|l|}{ Glucose (mmol/l) } \\
\hline CD & $4.71 \pm 0.39$ & $4.24 \pm 0.90$ & $4.83 \pm 0.87$ & $5.24 \pm 1.00$ & $4.65 \pm 0.71$ & $4.77 \pm 0.57$ \\
\hline HSFD & $5.12 \pm 0.84$ & $5.97 \pm 0.73 *$ & $6.88 \pm 0.57 *$ & $8.89 \pm 2.05 * *$ & $9.54 \pm 2.12 * *$ & $10.27 \pm 2.25$ ** \\
\hline HSFD+Ibrolipim & $4.78 \pm 0.62$ & $4.41 \pm 1.45$ & $4.96 \pm 1.09 \#$ & $5.89 \pm 0.50^{\#}$ & $4.85 \pm 1.10^{\# \#}$ & $4.75 \pm 0.45$ \\
\hline \multicolumn{7}{|l|}{ Insulin (U/I) } \\
\hline CD & $6.97 \pm 0.33$ & $7.31 \pm 0.94$ & $7.50 \pm 0.93$ & $8.68 \pm 0.82$ & $7.25 \pm 0.80$ & $7.65 \pm 1.33$ \\
\hline HSFD & $7.47 \pm 1.16$ & $9.12 \pm 1.63$ & $15.12 \pm 3.22 *$ & $21.16 \pm 5.08 *$ & $24.43 \pm 3.55^{* *}$ & $17.43 \pm 3.80 * *$ \\
\hline HSFD+Ibrolipim & $7.65 \pm 0.91$ & $8.73 \pm 1.52$ & $9.43 \pm 0.84^{\#}$ & $10.95 \pm 2.95 \#$ & $10.30 \pm 3.57^{\# \#}$ & $10.34 \pm 2.71 \#$ \\
\hline \multicolumn{7}{|c|}{ Homeostatic model assessment } \\
\hline CD & $1.38 \pm 0.18$ & $1.54 \pm 0.50$ & $1.63 \pm 0.47$ & $1.97 \pm 0.63$ & $1.51 \pm 0.32$ & $1.64 \pm 0.45$ \\
\hline HSFD & $1.59 \pm 0.26$ & $2.29 \pm 0.39$ & $4.38 \pm 1.05^{* *}$ & $7.04 \pm 1.05^{* *}$ & $10.40 \pm 1.75^{* *}$ & $7.83 \pm 1.63 * *$ \\
\hline HSFD+lbrolipim & $1.56 \pm 0.26$ & $1.87 \pm 0.56$ & $2.11 \pm 0.59$ \#\# & $2.89 \pm 0.51$ & $2.16 \pm 0.45^{\# \#}$ & $2.62 \pm 0.70$ \#\# \\
\hline \multicolumn{7}{|c|}{ Triglyceride (mmol/l) } \\
\hline$C D$ & $0.59 \pm 0.04$ & $0.59 \pm 0.06$ & $0.63 \pm 0.10$ & $0.69 \pm 0.16$ & $0.71 \pm 0.15$ & $0.73 \pm 0.13$ \\
\hline HSFD & $0.59 \pm 0.05$ & $0.94 \pm 0.07^{* *}$ & $1.50 \pm 0.18^{* *}$ & $1.87 \pm 0.14^{* *}$ & $2.03 \pm 0.42^{* *}$ & $2.10 \pm 0.32 * *$ \\
\hline HSFD+Ibrolipim & $0.58 \pm 0.04$ & $0.60 \pm 0.01 \#$ & $0.78 \pm 0.08$ \#\# & $0.87 \pm 0.17^{\# \#}$ & $1.03 \pm 0.25$ \#\# & $1.10 \pm 0.35^{\# \#}$ \\
\hline \multicolumn{7}{|c|}{ Total cholesterol (mmol/l) } \\
\hline CD & $2.06 \pm 0.34$ & $1.99 \pm 0.33$ & $2.01 \pm 0.35$ & $1.68 \pm 0.21$ & $1.82 \pm 0.49$ & $2.07 \pm 0.46$ \\
\hline HSFD & $2.31 \pm 0.44$ & $6.24 \pm 1.77^{* *}$ & $9.06 \pm 1.44^{* *}$ & $11.20 \pm 2.02 * *$ & $15.23 \pm 2.00 * *$ & $20.45 \pm 2.83^{* *}$ \\
\hline HSFD+Ibrolipim & $2.29 \pm 0.55$ & $8.02 \pm 2.15^{\#}$ & $11.99 \pm 2.15^{\#}$ & $13.55 \pm 3.12^{\#}$ & $16.39 \pm 4.23$ & $22.14 \pm 4.59$ \\
\hline \multicolumn{7}{|c|}{ HDL cholesterol (mmol/l) } \\
\hline CD & $0.78 \pm 0.14$ & $0.76 \pm 0.18$ & $0.85 \pm 0.17$ & $1.02 \pm 0.12$ & $0.81 \pm 0.16$ & $0.96 \pm 0.29$ \\
\hline HSFD & $0.89 \pm 0.12$ & $1.09 \pm 0.18 *$ & $1.37 \pm 0.28 *$ & $1.82 \pm 0.53 *$ & $2.00 \pm 0.39 * *$ & $1.83 \pm 0.36^{* *}$ \\
\hline HSFD+Ibrolipim & $0.79 \pm 0.15$ & $1.23 \pm 0.21$ & $2.29 \pm 0.43$ \#\# & $2.85 \pm 0.47^{\# \#}$ & $2.92 \pm 0.54$ \#\# & $2.86 \pm 0.46$ \#\# \\
\hline
\end{tabular}


Table 2 Renal function in Chinese Bama minipigs

\begin{tabular}{|c|c|c|c|c|}
\hline Parameters & Baseline & 2 months & 4 months & 5 months \\
\hline \multicolumn{5}{|c|}{ Urinary microalbumin/creatinine ratio $(\mathrm{mg} / \mathrm{g})$} \\
\hline$C D$ & $12.26 \pm 2.54$ & $12.77 \pm 3.33$ & $13.52 \pm 4.67$ & $12.60 \pm 3.27$ \\
\hline HSFD & $12.73 \pm 3.14$ & $14.16 \pm 3.53$ & $25.13 \pm 4.65 *$ & $48.08 \pm 11.77^{* *}$ \\
\hline HSFD+Ibrolipim & $13.18 \pm 3.45$ & $12.66 \pm 4.01$ & $17.24 \pm 5.63$ \# & $24.14 \pm 7.99$ \#\# \\
\hline \multicolumn{5}{|c|}{ Plasma creatinine $(\mu \mathrm{mol} / \mathrm{l})$} \\
\hline$C D$ & $28.56 \pm 5.54$ & $28.97 \pm 7.44$ & $28.81 \pm 6.02$ & $29.69 \pm 3.81$ \\
\hline HSFD & $26.67 \pm 6.53$ & $27.71 \pm 6.36$ & $30.76 \pm 8.91$ & $33.38 \pm 9.10$ \\
\hline HSFD+Ibrolipim & $28.77 \pm 7.34$ & $30.25 \pm 6.17$ & $31.56 \pm 7.43$ & $32.19 \pm 8.01$ \\
\hline \multicolumn{5}{|c|}{ Urinary creatinine ( $\mathrm{mmol} / \mathrm{l})$} \\
\hline$C D$ & $3.77 \pm 0.53$ & $4.08 \pm 0.84$ & $4.13 \pm 1.00$ & $4.43 \pm 0.87$ \\
\hline HSFD & $4.05 \pm 0.72$ & $4.20 \pm 0.92$ & $4.08 \pm 0.76$ & $4.71 \pm 0.69$ \\
\hline HSFD+Ibrolipim & $3.92 \pm 0.68$ & $4.17 \pm 0.96$ & $4.20 \pm 1.01$ & $4.48 \pm 0.49$ \\
\hline
\end{tabular}

Values are means $\pm \mathrm{SD}, \mathrm{n}=5$ in each group; ${ }^{*} P<0.05,{ }^{*} P<0.01$ vs. CD group; $P<0.05$, \#\# $P<0.01$ vs. HSFD group.

Oil Red O staining of kidney sections showed minimal or absent lipid deposits in the kidneys of the CD group (Figure 1A; the percentage of positive area: $0.15 \% \pm$ $0.04 \%$ ) and the HSFD+Ibrolipim group (Figure 1C; $0.42 \%$ $\pm 0.13 \%, P<0.001 v s$. HSFD group). On the other hand, marked deposition in tubular epithelial cells and small amounts in glomeruli of Oil Red O-stainable lipid were observed in HSFD group (Figure 1B; $1.14 \% \pm 0.30 \%, P<$ 0.001 vs. CD group). Corresponding to biochemical analysis of lipid composition, these results strongly indicated that there were excessive amounts of lipid accumulation in the kidneys of HSFD pigs, and the accumulation could be eliminated by treating with Ibrolipim.

\section{Effects of Ibrolipim on plasma and renal LPL activity in minipigs}

Postprandial postheparin plasma LPL activity significantly increased in the HSFD group compared with the CD group, and even more in the HSFD+Ibrolipim group than the HSFD group (Table 3).

Renal tissue LPL activity decreased $28.57 \%$ in the HSFD group compared with the CD group, and increased 100\% after the treatment with Ibrolipim compared with the HSFD group (Table 3 ).

\section{Effects of Ibrolipim on renal LPL mRNA and protein} expression in minipigs

Quantitative real-time PCR analysis showed that LPL mRNA levels decreased $28.81 \%$ in the kidney tissues of the HSFD group compared with the CD group. In contrast, it increased $61.51 \%$ in the HSFD+Ibrolipim group compared with the HSFD group (Figure 2).

Western blot analysis showed that the protein expression of LPL was decreased in the kidneys of HSFD vs. CD minipigs, and HSFD-induced down-regulation of LPL was increased by the administration of Ibrolipim (Figure 3).

Immunohistochemical analysis showed that HSFD decreased the immunoreactivity of LPL in the glomerular endothelial, parietal epithelial, and tubular epithelial cells compared with the CD group. Ibrolipim reversed the decrease compared with the HSFD group (Figure 4).

It was worthy to note that the reduction in LPL protein expression was accompanied by a parallel reduction in LPL mRNA of renal tissues for the HSFD group. In contrast, Ibrolipim stimulated the diet-induced downregulation of LPL in the kidney.

\section{Effects of Ibrolipim on renal morphology in minipigs}

HE staining clearly revealed glomerular hypertrophy, mesangial expansion, parietal layer of Bowman's capsule thickening, inflammatory cell infiltration, and dilated tubules within hyaline casts in the HSFD-fed minipigs (Figure 5B) compared with the control minipigs (Figure 5A). These abnormalities associated with HSFD feeding were attenuated by Ibrolipim treatment (Figure 5C).

Table 3 Renal lipid contents, and renal and plasma LPL activities in Chinese Bama minipigs

\begin{tabular}{ccccc}
\hline Groups & $\begin{array}{c}\text { Renal triglyceride content } \\
\text { (mg/g protein) }\end{array}$ & $\begin{array}{c}\text { Renal cholesterol content } \\
\text { (mg/g protein) }\end{array}$ & $\begin{array}{c}\text { Renal lipoprotein lipase activity } \\
\text { (U/g protein) }\end{array}$ & $\begin{array}{c}\text { Plasma lipoprotein lipase } \\
\text { activity (U/ml) }\end{array}$ \\
\hline CD & $7.17 \pm 1.53$ & $7.49 \pm 1.92$ & $0.07 \pm 0.01$ & $7.34 \pm 1.72$ \\
HSFD & $15.99 \pm 2.59 * *$ & $18.69 \pm 3.99 * *$ & $0.05 \pm 0.01 *$ & $31.88 \pm 8.14 * *$ \\
HSFD & $7.92 \pm 1.45^{* \#}$ & $9.00 \pm 2.83^{* \#}$ & $0.10 \pm 0.01^{\# \#}$ & $47.55 \pm 5.388^{\# \#}$ \\
+lbrolipim & & & & \\
\hline
\end{tabular}

Values are means $\pm \mathrm{SD}, \mathrm{n}=5$ in each group; ${ }^{*} P<0.05$, ** $P<0.01$ vs. CD group; \#\# $P<0.01$ vs. HSFD group. 

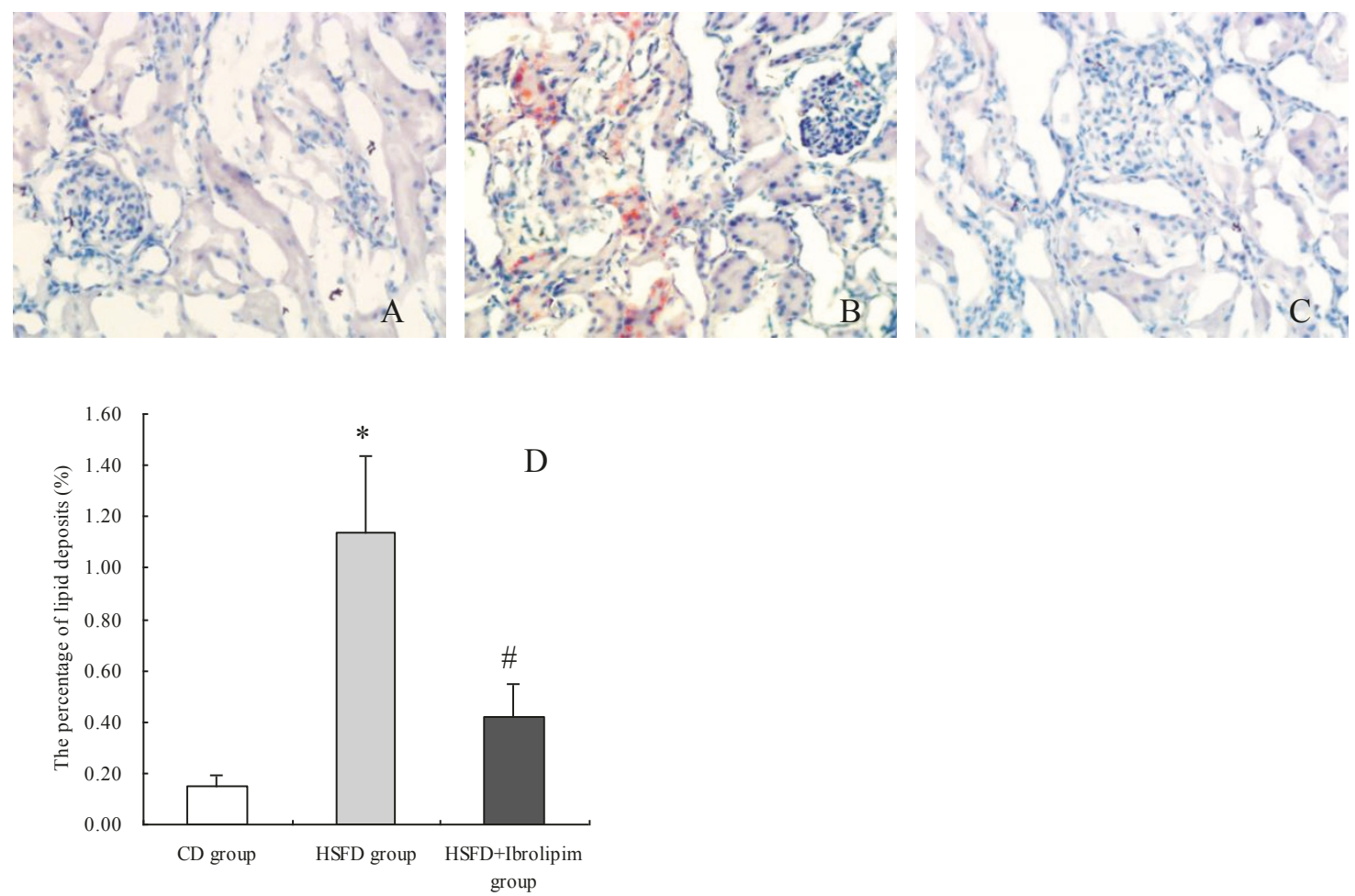

Figure 1 Representative photomicrographs of Oil Red $\mathrm{O}$ staining in frozen kidney sections from Chinese Bama minipigs. No apparent lipid droplets, appeared as red spots, were observed in the control group (1A) and the HSFD+lbrolipim group (1C). There were marked deposition in tubular epithelial cells and small amounts in glomeruli of Oil Red O-stainable lipid in the HSFD group (1B) ( $\times 200$ magnification). (1D) The percentage of Oil Red O-positive area was used for comparison (mean \pm SD). ${ }^{*} P<0.01$ vs. CD group; \# $P<0.01$ vs. HSFD group.

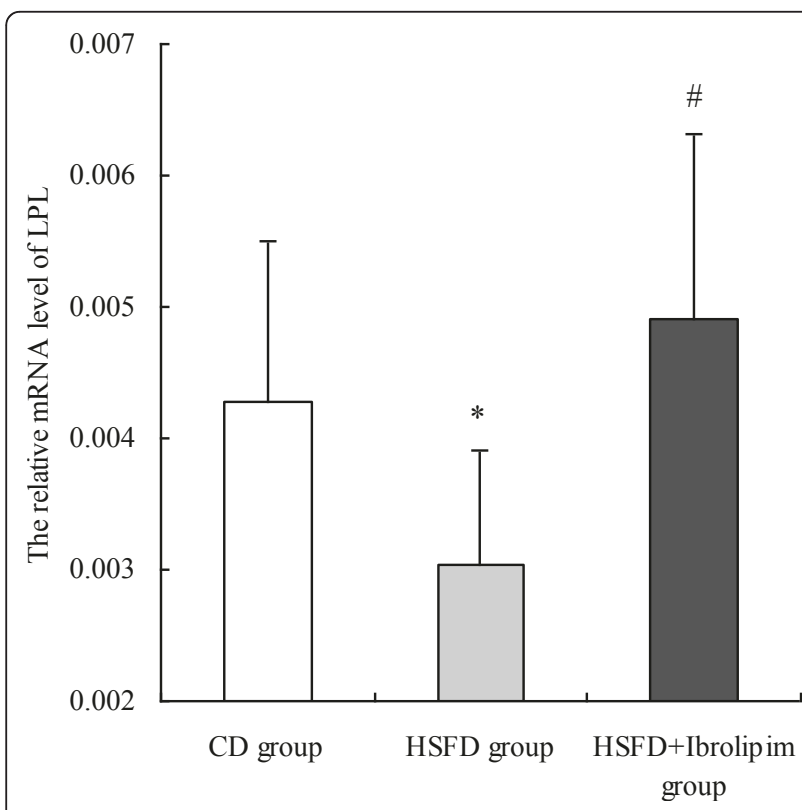

Figure 2 The mRNA expression of lipoprotein lipase in the kidneys of Chinese Bama minipigs performed by real-time PCR The relative mRNA levels, normalized to an internal control $\beta$-actin, were calculated according to the formula $2^{-\triangle C T}$. Data are the means $\pm \mathrm{SD}, * P<0.01$ vs. CD group; $P<0.01$ vs. HSFD group.

\section{Correlations between contents of triglyceride and} cholesterol and LPL activity in kidneys

As shown in Figure 6, triglyceride content and cholesterol content were inversely correlated with LPL activity in kidneys $(r=-0.77, P=0.001 ; r=-0.71, P=0.003$, respectively).

\section{Discussion}

In our research, HSFD-feeding to minipigs for 5 months induced weight gain, hyperglycemia, hyperinsulinemia, insulin resistance, hypertriglyceridemia, hypercholesterolemia and microalbuminuria. The diet induced excessive amounts of lipid deposits in the kidney, as shown by increased Oil Red $\mathrm{O}$ staining and significantly higher renal contents of triglyceride and cholesterol. We also found that HSFD resulted in renal morphological abnormality, which was characterized by glomerular hypertrophy, mesangial expansion, inflammatory cell infiltration and dilated tubules within hyaline casts. Results from our study do confirm those previous findings and support the theory that diet-induced lipid metabolism disorder and excessive renal lipid accumulation are contributing to the development of $\mathrm{DN}$ $[3,6,8,29]$. 


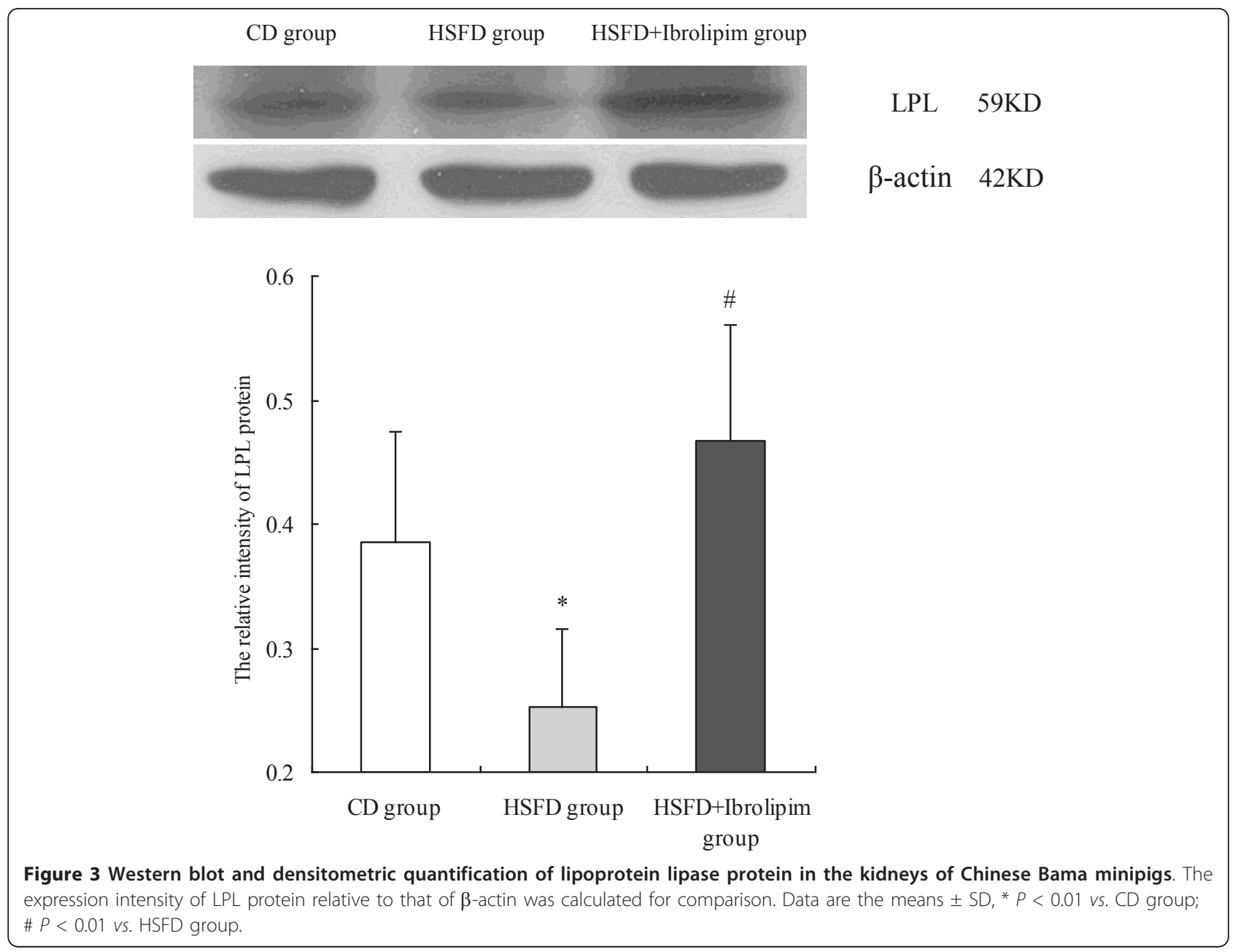

Furthermore, our study has the following novel findings. The first is that the elevation of renal triglyceride and cholesterol contents is correlated with a significant reduction in renal LPL activity (Figure 6). This is accompanied by a parallel reduction in mRNA and protein expression of renal LPL. The specific immunolocalization with anti-LPL antibodies by using immunohistochemistry is expressed in the glomerular endothelial, parietal epithelial, and tubular epithelial cells, where ectopic lipid deposition is observed in HSFD-fed minipigs with Oil Red O staining. However, there are conflicting reports that LPL is expressed by different types of renal cells, and its mRNA, mass and activity in kidneys vary widely among different species,
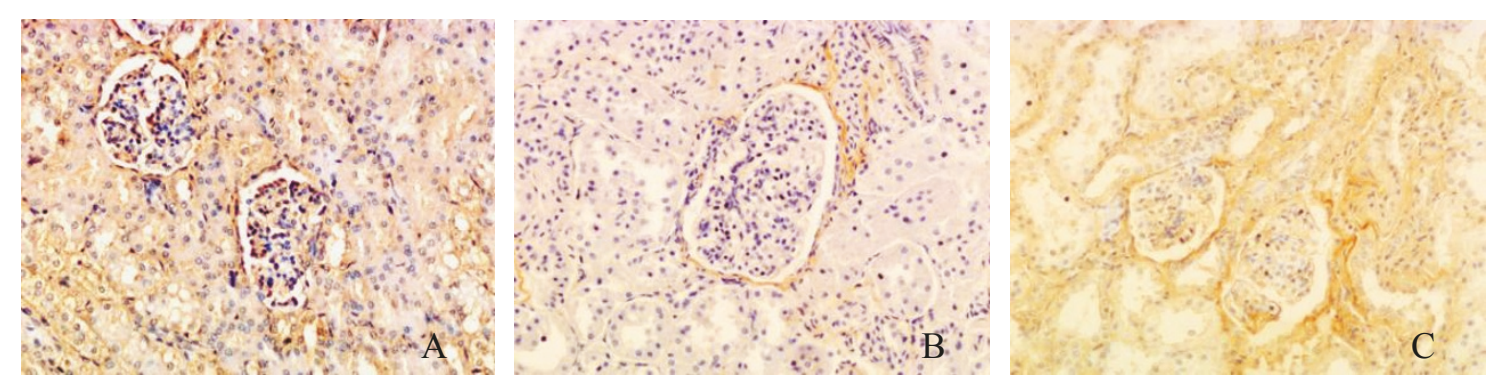

Figure 4 Representative photomicrographs of immunohistochemical staining for lipoprotein lipase protein in kidney sections from Chinese Bama minipigs. The positive staining appeared as brown in the glomerular and tubulointerstitial cells of the control group (4A), the HSFD group (4B) and the HSFD+Ibrolipim group (4C). Original magnification $\times 200$. 

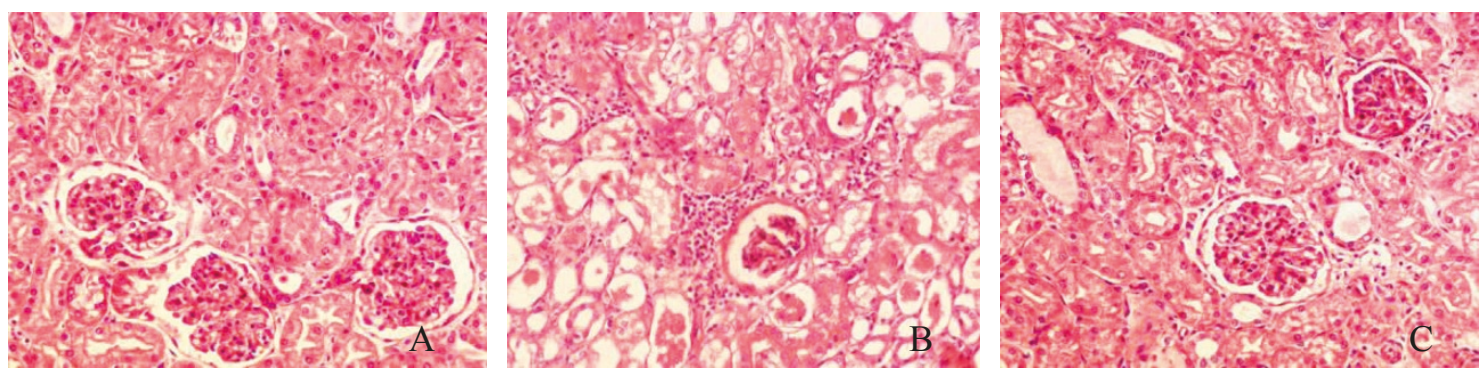

Figure 5 Representative photomicrographs of HE staining in kidney sections from Chinese Bama minipigs. (5A) Control group; (5B) HSFD group; (5C) HSFD+Ibrolipim group. Original magnification $\times 200$.

such as human, mink, mouse, rat and Chinese hamster [11,12,30-33]. Mesangial cells, but not epithelial cells, express LPL mRNA in human and rat [11]. Immunostaining for kidney LPL indicates that the enzyme is present in tubular epithelial cells of mouse and mink [12] and vascular endothelium of glomeruli in guinea pig [34]. To our knowledge, the present study is the first to report that the expression and activity of LPL are evaluated in the kidney of Chinese Bama minipigs, and down-regulated by HSFD for 5 months.

The second novel finding of our study is that HSFD feeding increases postprandial postheparin plasma LPL activity while decreases the mRNA and protein expression and activity of renal LPL. However, the mechanism for this phenomenon is not clear. Previous study has shown that plasma LPL activity increases and reaches a maximum at $6 \mathrm{~h}$ after intake of the oral fat load in humans [35]. Moreover, LPL activity is regulated according to nutritional state in a tissue-specific manner [10]. Adipose tissue LPL activity rises rapidly after feeding by a post-transcriptional mechanism in guinea pigs and mice [36,37]. In SD rats, a high-fat diet differentially affects LPL activity in muscle and adipose tissue, reducing the former and greatly increasing the latter, which tends to induce fat storage and insulin resistance [22]. It is, therefore, speculated that HFSD seems to promote the release of LPL from peripheral tissues such as adipose tissue to blood.

Several studies have revealed that peripheral catabolism of triglyceride-laden lipoproteins (i.e., CM and VLDL) is impaired and postheparin LPL activity and mass are reduced in clinical nephrosis $[15,38,39]$. In animal models of kidney disease, significant reduction of LPL activity, mRNA level or protein mass is observed in the cardiac muscle, skeletal muscle and adipose tissues [16-18,33,40,41]. These studies are consistent with an important role for acquired LPL deficiency in the pathogenesis of dyslipidemia and renal diseases. In sharp contrast, studies in vitro have shown that LPL enhances the binding of VLDL to mesangial cells via a heparan sulfate-dependent mechanism [13], increases cellular triglyceride accumulation via enzymolysis [14], and stimulates both the proliferation of these cells and the expression of PDGF [13]. In baby hamster kidney (BHK)

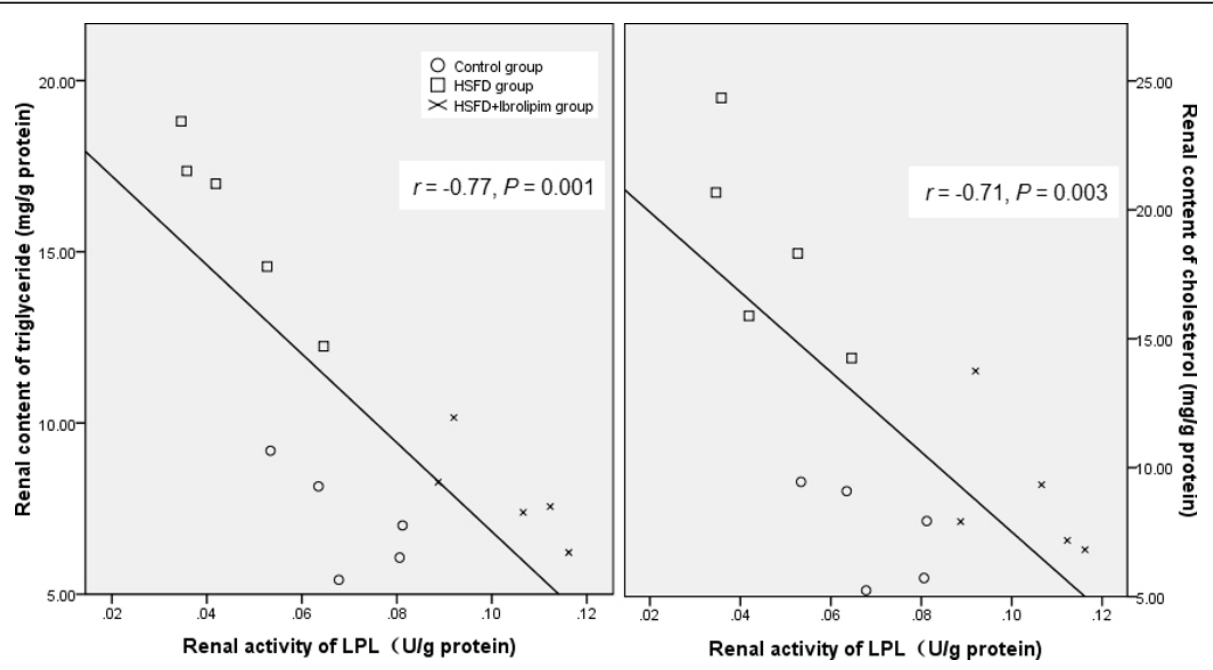

Figure 6 Correlations between contents of triglyceride and cholesterol and LPL activity in kidney. 
and human embryonal kidney 293 (HEK 293) cells, the stimulating effect of LPL on $\mathrm{HDL}_{3}$ selective cholesteryl ester uptake is independent of lipolysis [42]. Above all, both clinical and experimental studies are still producing conflicting findings that LPL may have pro-nephrogenic or anti-nephrogenic effects.

Our minipigs with diet-induced DN exhibits a significant LPL deficiency in kidney tissue per se, and this seems to imply that renal LPL have beneficial effects on lipid metabolism and renal protection. Therefore, LPL activator might protect the kidney from injury to lipid accumulation. In fact, losartan improves lipid metabolism abnormality and increases LPL activity in adipose tissue of rats with renal artery stenosis [43]. Oral administration of $100 \mathrm{mg} / \mathrm{kg}$ Glycyrrhizic acid up-regulates the LPL mRNA expression in the kidney of high-fat diet induced obese rats [33].

The third novel finding of the present study is that LPL selective activator Ibrolipim, given for 5 months in combination with HSFD, significantly reduces hyperglycemia, hyperinsulinemia, insulin resistance, hypertriglyceridemia, microalbuminuria, renal fat accumulation, and improves pathological injury, all consistent with the increase in renal LPL activity and expression. These existing evidences suggest that the renoprotective effects of Ibrolipim on suppressing triglyceride and cholesterol accumulation in kidney may be directly attributable to the activation of the downregulation of renal LPL mRNA and protein and activity induced by HSFD.

Of course, additional mechanisms may be responsible for the effects of Ibrolipim. Firstly, Ibrolipim reduces ectopic lipid deposition in the heart, skeletal muscle, liver and pancreas in diet-induced diabetic animal model $[22,23]$ through increasing LPL activity in soleus skeletal muscle and myocardium with an increase in fat oxidation [22]. Therefore, it is possible that the increase of renal LPL expression and activity can also lead to an increase of triglyceride utilization in kidney. Secondly, Ibrolipim has been proved to be highly effective in increasing plasma HDL-C through mediating reverse cholesterol transport from peripheral tissues to the liver to protect against the excessive accumulation of cholesterol [44]. Thirdly, Ibrolipim exhibits the significant inhibitory activity of in vitro mesangial cell proliferation [45]. Further studies are warranted to determine the mechanisms of Ibrolipim in the suppression of renal lipid accumulation and renal disease.

\section{Conclusions}

In summary, renal LPL plays a crucial role in the pathophysiology of lipid metabolism and the pathogenesis of nephropathy, and activation of renal LPL is renoprotective in diet-induced DN. However, the fact that our and others' studies are still producing conflicting findings with respect to the role of LPL only suggests that our understanding of LPL and Ibrolipim are not thorough. It is undeniable that Ibrolipim, a lipoprotein lipase agonist, has been proved to have potential benefit for prevention and treatment of $\mathrm{DN}$.

\section{List of abbreviations}

CD: control diet; CM: chylomicrons; Cr: creatinine; DN: diabetic nephropathy; HDL-C: high-density lipoprotein cholesterol; HOMA: homeostatic model assessment; HSFD: high-sucrose and high-fat diet; LPL: lipoprotein lipase; mALB: microalbumin; PDGF: platelet-derived growth factor; TC: total cholesterol; TG: triglyceride; VLDL: very-low-density lipoproteins.

\section{Acknowledgements}

The research is funded by Hunan Provincial Science and Technology Department (2009-17 and 2010TT1008) and Guangdong Provincial Health Department of China (A2009692). We are grateful to Prof. Xiutian Zhou and Ying Song (Department of Pathology, University of South China) for pathological assistance and to Miss. Rong He (Department of English, Medical College of Shaoguan University) for language help.

\section{Author details}

${ }^{1}$ Department of Laboratory Animal Science, School of Pharmacy and Life Science, University of South China, Hengyang, Hunan 421001, China. ${ }^{2}$ Department of Biochemistry, Medical College, Shaoguan University, Shaoguan, Guangdong 512026, China. ${ }^{3}$ Key Laboratory for Atherosclerology of Hunan Province, Institute of Cardiovascular Research, University of South China, Hengyang, Hunan 421001, China.

\section{Authors' contributions}

$\mathrm{YL}$ and ZBW contributed to design, animal experiment, analysis and writing of the manuscript; WDY to design and planning of the study; QKL, MBC, JY, HGL, CZ and XHZ to animal experiment, data collection and analysis. All authors read and approved the final manuscript.

\section{Competing interests}

The authors declare that they have no competing interests.

Received: 18 May 2011 Accepted: 16 July 2011 Published: 16 July 2011

\section{References}

1. Oda H, Keane WF: Lipids in progression of renal disease. Kidney Int Suppl 1997, 62:S36-S38.

2. Keane WF: The role of lipids in renal disease: future challenges. Kidney Int Supp/ 2000, 75:S27-S31.

3. Wang Z, Jiang T, Li J, Proctor G, McManaman JL, Lucia S, Chua S, Levi M: Regulation of renal lipid metabolism, lipid accumulation, and glomerulosclerosis in FVB ${ }^{d b / d b}$ mice with type 2 diabetes. Diabetes 2005, 54:2328-2335

4. Kasiske BL, O'Donnell MP, Schmitz PG, Kim Y, Keane WF: Renal injury of diet-induced hypercholesterolemia in rats. Kidney Int 1990, 37:880-891.

5. Guijarro C, Kasiske BL, Kim Y, O'Donnell MP, Lee HS, Keane WF: Early glomerular changes in rats with dietary-induced hypercholesterolemia. Am J Kidney Dis 1995, 26:152-161.

6. Jiang T, Wang Z, Proctor G, Moskowitz S, Liebman SE, Rogers T, Lucia MS, Li J, Levi M: Diet-induced obesity in C57BL/6J mice causes increased renal lipid accumulation and glomerulosclerosis via a sterol regulatory element-binding protein-1c-dependent pathway. J Biol Chem 2005, 280:32317-32325.

7. Li Q, Yin W, Cai M, Liu Y, Hou H, Shen Q, Zhang C, Xiao J, Hu X, Wu Q, Funaki M, Nakaya Y: NO-1886 suppresses diet-induced insulin resistance and cholesterol accumulation through STAT5-dependent upregulation of IGF1 and CYP7A1. J Endocrinol 2010, 204:47-56.

8. Liu Y, Wang Z, Yin W, Li Q, Cai M, Zhang C, Xiao J, Hou H, Li H, Zu X: Severe insulin resistance and moderate glomerulosclerosis in a minipig model induced by high-fat/ high-sucrose/ high-cholesterol diet. Exp Anim 2007, 56:11-20. 
9. Goldberg IJ: Lipoprotein lipase and lipolysis: central roles in lipoprotein metabolism and atherogenesis. J Lipid Res 1996, 37:693-707.

10. Preiss-Landl K, Zimmermann R, Hämmerle G, Zechner R: Lipoprotein lipase: the regulation of tissue specific expression and its role in lipid and energy metabolism. Curr Opin Lipidol 2002, 13:471-481.

11. Irvine SA, Martin J, Hughes TR, Ramji DP: Lipoprotein lipase is expressed by glomerular mesangial cells. Int J Biochem Cell Biol 2006, 38:12-16.

12. Ruge T, Neuger L, Sukonina V, Wu G, Barath S, Gupta J, Frankel B, Christophersen B, Nordstoga K, Olivecrona T, Olivecrona G: Lipoprotein lipase in the kidney: activity varies widely among animal species. Am J Physiol Renal Physiol 2004, 287:F1131-F1139.

13. Stevenson FT, Shearer GC, Atkinson DN: Lipoprotein-stimulated mesangial cell proliferation and gene expression are regulated by lipoprotein lipase. Kidney Int 2001, 59:2062-2068.

14. Li J, Li H, Wen YB, Li XW: Very-low-density lipoprotein-induced triglyceride accumulation in human mesangial cells is mainly mediated by lipoprotein lipase. Nephron Physiol 2008, 110:p1-p10.

15. Marsh JB: Lipoprotein metabolism in the nephrotic syndrome. Front Biosci 2002, 7:e326-e338.

16. Sato T, Liang K, Vaziri ND: Down-regulation of lipoprotein lipase and VLDL receptor in rats with focal glomerulosclerosis. Kidney Int 2002, 61:157-162.

17. Liang K, Vaziri ND: Gene expression of lipoprotein lipase in experimental nephrosis. J Lab Clin Med 1997, 130:387-394.

18. Vaziri ND, Liang K: Down-regulation of tissue lipoprotein lipase expression in experimental chronic renal failure. Kidney Int 1996, 50:1928-1935.

19. Tsutsumi K, Inoue Y, Shima A, Iwasaki K, Kawamura M, Murase T: The novel compound NO-1886 increases lipoprotein lipase activity with resulting elevation of high density lipoprotein cholesterol, and long-term administration inhibits atherogenesis in the coronary arteries of rats with experimental atherosclerosis. J Clin Invest 1993, 92:411-417.

20. Tsutsumi K, Inoue Y, Shima A, Murase T: Correction of hypertriglyceridemia with low high-density lipoprotein cholesterol by the novel compound NO-1886, a lipoprotein lipase-promoting agent, in STZ-induced diabetic rats. Diabetes 1995, 44:414-417.

21. Yin WD, Tsutsumi K: Lipoprotein lipase activator NO-1886. Cardiovasc Drug Rev 2003, 21:133-142

22. Kusunoki M, Hara T, Tsutsumi K, Nakamura T, Miyata T, Sakakibara F, Sakamoto S, Ogawa H, Nakaya Y, Storlien LH: The lipoprotein lipase activator, NO-1886, suppresses fat accumulation and insulin resistance in rats fed a high-fat diet. Diabetologia 2000, 43:875-880.

23. Yin W, Liao D, Kusunoki M, Xi S, Tsutsumi K, Wang Z, Lian X, Koike T, Fan J, Yang Y, Tang C: NO-1886 decreases ectopic lipid deposition and protects pancreatic beta cells in diet-induced diabetic swine. J Endocrinol 2004, 180:399-408.

24. Nakayama K, Hara T, Kusunoki M, Tsutsumi K, Minami A, Okada K, Sakamoto S, Ohnaka M, Miyata T, Nakamura T, Aoki T, Fukatsu A, Nakaya Y, Kakumu S: Effect of the lipoprotein lipase activator NO-1886 on adriamycin-induced nephrotic syndrome in rats. Metabolism 2000 49:588-593.

25. Bonora E, Targher G, Alberiche M, Bonadonna RC, Saggiani F, Zenere MB, Monauni T, Muggeo M: Homeostasis model assessment closely mirrors the glucose clamp technique in the assessment of insulin sensitivity: studies in subjects with various degrees of glucose tolerance and insulin sensitivity. Diabetes Care 2000, 23:57-63.

26. Murase $\mathrm{T}$, Uchimura $\mathrm{H}$ : A selective decline of postheparin plasma hepatic triglyceride lipase in hypothyroid rats. Metabolism 1980, 29:797-801.

27. Nathan DM, Rosenbaum C, Protasowicki VD: Single-void urine samples can be used to estimate quantitative microalbuminuria. Diabetes Care 1987, 10:414-418.

28. Bligh $E G$, Dyer WJ: A rapid method of total lipid extraction and purification. Can J Biochem Physiol 1959, 37:911-917.

29. Amin KA, Kamel HH, Abd Eltawab MA: Protective effect of Garcinia against renal oxidative stress and biomarkers induced by high fat and sucrose diet. Lipids Health Dis 2011, 10:6.

30. Kirchgessner TG, LeBoeuf RC, Langner CA, Zollman S, Chang CH, Taylor BA, Schotz MC, Gordon JI, Lusis AJ: Genetic and developmental regulation of the lipoprotein lipase gene: loci both distal and proximal to the lipoprotein lipase structural gene control enzyme expression. J Biol Chem 1989, 264:1473-1482
31. Lindberg A, Nordstoga K, Christophersen B, Savonen R, van Tol A, Olivecrona G: A mutation in the lipoprotein lipase gene associated with hyperlipoproteinemia type I in mink: studies on lipid and lipase levels in heterozygotes. Int J Mol Med 1998, 1:529-538.

32. Lim WY, Chia YY, Liong SY, Ton SH, Kadir KA, Husain SN: Lipoprotein lipase expression, serum lipid and tissue lipid deposition in orally-administered glycyrrhizic acid-treated rats. Lipids Health Dis 2009, 8:31.

33. Eu CH, Lim WY, Ton SH, bin Abdul Kadir K: Glycyrrhizic acid improved lipoprotein lipase expression, insulin sensitivity, serum lipid and lipid deposition in high-fat diet-induced obese rats. Lipids Health Dis 2010, 9:81.

34. Camps L, Reina M, Llobera M, Vilaró S, Olivecrona T: Lipoprotein lipase: cellular origin and functional distribution. Am J Physiol 1990, 258 : C673-C681.

35. Karpe $F$, Olivecrona $T$, Walldius $G$, Hamsten A: Lipoprotein lipase in plasma after an oral fat load: relation to free fatty acids. J Lipid Res 1992, 33:975-984.

36. Semb H, Olivecrona T: Nutritional regulation of lipoprotein lipase in guinea pig tissues. Biochim Biophys Acta 1986, 876:249-255.

37. Ruge $T, W u$ G, Olivecrona $T$, Olivecrona G: Nutritional regulation of lipoprotein lipase in mice. Int J Biochem Cell Biol 2004, 36:320-329.

38. Kashyap ML, Srivastava LS, Hynd BA, Brady D, Perisutti G, Glueck CJ, Gartside PS: Apolipoprotein CII and lipoprotein lipase in human nephrotic syndrome. Atherosclerosis 1980, 35:29-40.

39. Antikainen M, Holmberg C, Olivecrona T, Bengtsson-Olivecrona G, Labeur C, Rosseneu M, Taskinen MR: Changes in biological activity and immunoreactive mass of lipoprotein lipase in congenital nephrosis: relationship to hypertriglyceridaemia. Eur J Clin Invest 1993, 23:368-374

40. Levy E, Ziv E, Bar-On H, Shafrir E: Experimental nephrotic syndrome: removal and tissue distribution of chylomicrons and very-low-density lipoproteins of normal and nephrotic origin. Biochim Biophys Acta 1990, 1043:259-266.

41. Vaziri ND, Wang $X Q$, Liang $K$ : Secondary hyperparathyroidism downregulates lipoprotein lipase expression in chronic renal failure. Am J Physiol 1997, 273:F925-F930.

42. Rinninger F, Brundert M, Brosch I, Donarski N, Budzinski RM, Greten H: Lipoprotein lipase mediates an increase in selective uptake of HDLassociated cholesteryl esters by cells in culture independent of scavenger receptor BI. J Lipid Res 2001, 42:1740-1751.

43. Saranteas T, Lolis E, Mourouzis C, Potamianou A, Tesseromatis C, Varonos D: Effect of losartan on insulin plasma concentrations and LPL activity in adipose tissue of hypertensive rats. Horm Metab Res 2003, 35:164-168.

44. Zhang C, Yin W, Liao D, Huang L, Tang C, Tsutsumi K, Wang Z, Liu Y, Li Q, Hou H, Cai M, Xiao J: NO-1886 upregulates ATP binding cassette transporter A1 and inhibits diet-induced atherosclerosis in Chinese Bama minipigs. J Lipid Res 2006, 47:2055-2063.

45. Kurogi Y, Miyata K, Okamura T, Hashimoto K, Tsutsumi K, Nasu M, Moriyasu M: Discovery of novel mesangial cell proliferation inhibitors using a three-dimensional database searching method. J Med Chem 2001, 44:2304-2307.

\section{doi:10.1186/1476-511X-10-117}

Cite this article as: Liu et al.: Preventive effect of Ibrolipim on suppressing lipid accumulation and increasing lipoprotein lipase in the kidneys of diet-induced diabetic minipigs. Lipids in Health and Disease 2011 10:117. 